\section{Increased Incidence of Gastrointestinal Side Effects in Patients Taking Hydroxychloroquine: A Brand-related Issue?}

\section{To the Editor:}

Hydroxychloroquine (HCQ) is a well-established drug used in the treatment of systemic lupus erythematosus (SLE). Lupus UK, a national registered charity supporting people who have SLE, has received a number of recent reports from patients who are experiencing new adverse effects from HCQ after being established on the treatment without any initial adverse effects These reports began in the first half of 2015 when Plaquenil (a brand name for HCQ) was discontinued ${ }^{1}$. At that time, many patients were switched to another brand of HCQ called Quinoric; subsequently, patients have frequently attributed side effects, mainly gastrointestinal (GI; such as dyspepsia, abdominal cramps, and dysgeusia), to this new brand of HCQ. We surveyed 128 patients attending the SLE clinic at City Hospital Birmingham, UK, over a 6-week period (June/July 2016) to examine whether there are brand-related differences in side effect prevalence for patients taking HCQ.

There is a wealth of evidence that supports the use of HCQ in the treatment of SLE, and careful consideration must be made in discontinuing its use. Its efficacy in treating mucocutaneous disease along with fatigue and serositis has been widely demonstrated ${ }^{2,3}$. HCQ is used mainly in the treatment of mild SLE, with strong evidence showing significant reductions in mortality, disease activity, flare rate, and the chance of renal disease ${ }^{4,5}$. It is one of the few drugs licensed for SLE and the most common antimalarial drug prescribed for the condition. Its use can be continued in more severe forms of the disease, in particular because of its steroid-sparing effect, as well as the synergistic effect it has with mycophenolate mofetil in renal disease $^{6}$. HCQ has also been demonstrated to be safe at time of conception, during pregnancy, and while breastfeeding, and it may reduce the likelihood of congenital heart block in anti-Ro-positive mothers ${ }^{7}$.

The vast majority of patients with SLE will at one time take HCQ, on average for 6 to 7 years $^{8}$. HCQ is generally better tolerated than other antimalarials such as chloroquine. The most common side effects are GI, although patients can also have headaches, tinnitus, itching, and rashes $^{2}$. In addition, it is important to note that HCQ can cause retinopathy with prolonged use. Patients who have been taking HCQ for over 7 years have been recommended to have formal eye screening for HCQ-related retinopathy, which is reversible if picked up early on active screening 9 .

At the City Hospital SLE clinic in Birmingham, we have noted an increase in the number of patients with SLE who have GI upset, to the point where additional investigations were thought necessary. As a result, we carried out a survey of our patients who are taking HCQ. It involved a short 5 -min self-reported questionnaire consisting of 8 questions. The initial questions asked the patients which brand of HCQ they were taking. At the time of this survey, HCQ was available as Plaquenil, Quinoric, or a generic HCQ, and patients were prompted with the use of pictures to help them identify which brands they had been taking. Once patients were able to provide information on which brands they had tried, they were asked to list any side effects they were experiencing and with which brand the side effects were the worst. Following that, patients were asked whether their side effects resolved following a switch of brands. Ethics approval was not required for the survey, in accordance with local policy.

Of the 128 patients surveyed, 116 had at one time taken (or were still taking) HCQ. Of those 116 patients, 38 reported any side effects, giving a prevalence of $33 \%$. Given the type of reported side effects from Quinoric, we focused our analysis on those patients who developed GI side effects while taking HCQ. Table 1 summarizes the number of patients who have tried the various brands of HCQ and those who have reported GI side effects. Analysis using Fisher's exact test showed that there was a significantly higher prevalence in GI side effects from Quinoric compared to Plaquenil and generic HCQ. Of note is that of the 13 patients who were switched from Quinoric to another brand of HCQ, all reported an improvement in GI side effects.

The results here suggest possible brand-related differences in the preva-
Table 1. Number of patients who have tried hydroxychloroquine (HCQ), and number of reported side effects.

\begin{tabular}{lcc}
\hline Drug & No. Patients & $\begin{array}{c}\text { No. Patients Reporting } \\
\text { GI Side Effects }\end{array}$ \\
\hline Plaquenil & 51 & $2(4 \%)$ \\
Quinoric & 79 & $14(18 \%)$ \\
Generic HCQ & 21 & $0(0 \%)$ \\
\hline
\end{tabular}

Fisher's exact test: for Quinoric vs Plaquenil, $\mathrm{p}=0.027$; for Quinoric vs generic HCQ, $\mathrm{p}=0.037$.

lence of GI side effects with HCQ. However, a controlled prospective study would be required to further explore and test formally the association between Quinoric and GI side effects, as observed in this analysis. The issue of brand-related side effects with HCQ is something clinicians should bear in mind, regardless of indication, and it is always wise to appreciate the patient's perspective on their medication. In our service, we have tended to switch patients experiencing GI side effects from Quinoric to other brands before discontinuing HCQ or ordering invasive investigations such as endoscopy.

AMAR SRINIVASA, BMBS, Academic Foundation Trainee Bmedsci (Hon), Department of Rheumatology, Birmingham City Hospital; SOFIA TOSOUNIDOU, MBBS, MRCP, Consultant in Rheumatology, Birmingham City Hospital; CAROLINE GORDON, MD, FRCP, Professor of Rheumatology, Department of Rheumatology, Birmingham City Hospital, Birmingham, UK. Address correspondence to A. Srinivasa, Department of Rheumatology, Birmingham City Hospital, Dudley Road, Birmingham B18 7QH, UK. E-mail: amarsrinivasa@nhs.net

\section{REFERENCES}

1. Plaquenil availability, Lupus UK. [Internet. Accessed November 9, 2016.] Available from: www.lupusuk.org.uk/plaquenil-availability/

2. Ruiz-Irastorza G, Ramos-Casals M, Brito-Zeron P, Khamashta MA. Clinical efficacy and side effects of antimalarials in systemic lupus erythematosus: a systematic review. Ann Rheum Dis 2010;69:20-8.

3. Wallace DJ. Antimalarial agents and lupus. Rheum Dis Clin North Am 1994;20:243-63.

4. Alarcón GS, McGwin G, Bertoli AM, Fessler BJ, Calvo-Alén J, Bastian HM, et al; LUMINA Study Group. Effect of hydroxychloroquine on the survival of patients with systemic lupus erythematosus: data from LUMINA, a multiethnic US cohort (LUMINA L). Ann Rheum Dis 2007;66:1168-72.

5. Costedoat-Chalumeau N, Galicier L, Aumaître O, Francès C, Le Guern V, Lioté F, et al. Hydroxychloroquine in systemic lupus erythematosus: results of a French multicentre controlled trial (PLUS Study). Ann Rheum Dis 2013;72:1786-92.

6. Kasitanon N, Fine DM, Haas M, Magder LS, Petri M. Hydroxychloroquine use predicts complete renal remission within 12 months among patients treated with mycophenolate mofetil therapy for membranous lupus nephritis. Lupus 2006;15:366-70.

7. Izmirly PM, Costedoat-Chalumeau N, Pisoni CN, Khamashta MA, Kim MY, Saxena A, et al. Maternal use of hydroxychloroquine is associated with a reduced risk of recurrent anti-SSA/ Ro-antibody-associated cardiac manifestations of neonatal lupus. Circulation 2012;126:76-82.

8. Wang C, Fortin PR, Li Y, Panaritis T, Gans M, Esdaile JM Discontinuation of antimalarial drugs in systemic lupus erythematosus. J Rheumatol 1999;26:808-15.

9. Wolfe F, Marmor MF. Rates and predictors of hydroxychloroquine retinal toxicity in patients with rheumatoid arthritis and systemic lupus erythematosus. Arthritis Care Res 2010;62:775-84.

J Rheumatol 2017;44:3; doi:10.3899/jrheum.161063

$$
\text { Personal non-commercial use only. The Journal of Rheumatology Copyright } \odot \text { 2017. All rights reserved. }
$$

